\title{
Preparation and Characterization of Sodium Alginate Polymeric Scaffold by Electrospinning Method for Skin Tissue Engineering Application
}

Sorour Jadbabaei

Azad University: Islamic Azad University

Farid Naiemi

Azad University: Islamic Azad University

Hassan Ebadi-Dehaghani

Azad University: Islamic Azad University

Majid Kolahdoozan ( $\nabla$ kolahdoozan@iaush.ac.ir)

Azad University: Islamic Azad University

\section{Research Article}

Keywords: sodium alginate, skin, tissue engineering, electrospinning, nanofiber

Posted Date: June 8th, 2021

DOI: https://doi.org/10.21203/rs.3.rs-574648/v1

License: (a) (i) This work is licensed under a Creative Commons Attribution 4.0 International License. Read Full License 


\section{Abstract}

Sodium alginate (SA) approved its high potential in tissue engineering and regenerative medicine. One of the main weaknesses of this polysaccharide is its low spinnability which nanofiber based scaffolds are the interest of scientists in biomedical engineering. The main aim of this study was to improve the spinnability of SA in combination with polyvinyl alcohol (PVA). It was also tried to optimize the main parameters in electrospinning of the optimized SA;PVA ratio including voltage, flow rate, and working space. To aim this, Response surface methodology under central composite design was employed to design the experiments scientifically. The final nanofiber scaffolds were studied using scanning electron microscopy, Fourier transform infrared spectroscopy, degradability, swelling, tensile strength, porosity, nanofiber diameter, contact angle, and cytotoxicity. Based on the results, the best ratio for SA:PVA was 1:6.5. The solution with this concentration was spinnable in various values for the process parameters. The fabricated scaffolds under these conditions revealed good physical, chemical, mechanical, and biological features. L929 cell lines revealed high viability during $48 \mathrm{~h}$ of culture. The results revealed the uniform and homogeneous nanofibers with the regular size distribution $(166 \mathrm{~nm})$ were obtained at $30 \mathrm{kV}$, $0.55 \mu \mathrm{l} / \mathrm{h}$, and $12.5 \mathrm{~cm}$. To sum up, the optimized ratio under the reported conditions can be a good biologically compatible candidate for skin tissue engineering.

\section{Introduction}

Tissue engineering (TE) is growing as a novel biomedical engineering area to redevelop newfangled material for substituting problematic or injured tissues [1, 2]. It comprises the construction of natural and/or synthetic structures, allows the combination of these materials with growth factors and/or signaling molecules to modulate cell proliferation and differentiation, and develop constructs mimicking the extracellular matrix (ECM) [3].

TE of skin substitutes signifies a potential foundation of improved treatment in fighting acute and chronic skin injuries [4]. Human skin is the widest organ of the body affected by injuries such as infection, burns, and disease [5]. There are no significant prototypes of engineered skin duplicate the composition, structure, organic constancy, or visual environment of healthy skin. Skin alternates should carry some essential physiognomies that comprise being simple to use [6].

Recent advances in skin TE have offered the potential to improve skin regeneration's clinical outcome [7, 8]. However, some deficiencies need to be addressed to provide substitutes with the painless and rapid healing process and encourage vascular, neural, and lymphatic networks, hair follicles, sebaceous and sweat glands [9]. Therefore, skin TE's ultimate goal is to fabricate a complicated scar-free skin substitute that can be transplanted in large quantities in only one surgical intervention with a minimum chance of rejection by the host's body $[10,11]$.

One of the main factors that influence graft success is the scaffolding technique. Some of the main criteria for designing a scaffold are cell adhesion, infiltration, proliferation, and differentiation, and 
capable of creating new tissue [12]. Various techniques have been reported for skin TE, including 3D printing, electrospinning, freeze-drying, gas foaming, etc. Scaffolds fabricated by electrospinning have been classified as an optimal scaffolding option with beneficial biological and mechanical properties [13, 14]. Electrospun nanofibers have exceptional properties such as a similar structure to the natural extracellular matrix (ECM) [15], permeability [16], and scar formation regulation [17]. This technique has been used extensively in the field of skin TE and various natural and synthetic biomaterials such as PCL [18], poly (lacto-co-glycolic acid) (PLGA) [19], polyvinyl alcohol (PVA) [20], sodium alginate(SA) [21], Bacterial cellulose [22], chitosan [23], and collagen [24] have been utilized to fabricate electrospun scaffolds (nicely reviewed by Quynh P. Pham [25]). Among them, SA and PVA were considered in tissue engineering.

There are several studies considering blends of SA and PVA for TE purposes. In research by Manikandan, G., et al. [26], scientists approved that SA/PVA composition can be a suitable candidate for liver TE. Liver cells had excellent adhesion. In the case of bone TE, SA/PVA 3D printed scaffold revealed its high potential in cell viability due to having homogeneous porosity and improved hydrophilic properties. The scaffold had excellent mechanical properties, and its modulus of elasticity showed promising results [27]. Similarity Coelho et al.[28] Showed that among the many polymer-based scaffolds fabricated for TE engineering, SA/PVA scaffolds are known to provide mechanical stability (high tensile strength and elongation at break), flexibility and slow degradation kinetics to the scaffolds. Also, Alhosseini et al.[29] Showed that in neural tissues, the scaffold microstructure, its three-dimensionality, and aligned fibers is as essential as its biological properties. Even though many materials and techniques have been employed in TE, SA/PVA based electrospun nanofibers have been shown to meet all the requirements. They can be tuned to fit specific alignments, porosity, and architectures while maintaining their flexibility, mechanical properties, and biological features. In research by Vig et al.[30], SA/PVA blend was used to fabricate electrospun scaffold for skin regeneration. The made scaffold revealed good mechanical properties, hydrophilicity, cell attachment, and cell growth. In another research in skin regeneration, SA/PVA scaffold showed that that the presence of SA inside the cross-linked polymeric network improved the active substance delivery properties of the hydrogel films. When more significant SA levels were applied, the hydrogel had an irregular surface structure, as revealed by SEM images.

According to the previous studies, the SA/PVA scaffold can be concluded depending on SA: PVA ratio has been nominated for both hard and soft tissues. Enhancement in SA content makes the scaffold suitable for soft tissues while increasing PVA content makes it eligible for hard tissues. Thereby, it is hypothesized that this blend can also be nominated for skin TE. Hence, the main aim of this study was to increase SA electrification capability by using PVA to fabricate a new electrospun SA/PVA scaffold capable of supporting the skin fibroblast cell for skin TE.

\section{Materials \& Methods}

\subsection{Chemicals}


Sodium alginate (SA, Sigma-Aldrich Canada Ltd, with a molecular weight of $216.12 \mathrm{~g} / \mathrm{mol}$ ) and polyvinyl alcohol (PVA, 99\%, Merck), and glutaraldehyde were purchased from a local supplier, TemadKala Co., Tehran, Iran. All the materials and the reagents were in analytical grade.

\subsection{Procedure}

In this research, it was tried to fabricate electrospun SA-based scaffold by optimization and characterization of the final formula and the main parameters in electrospinning including Pressure (P), Temperature (T), and Velocity (V). To aim this, as the step\#1, first the optimized formulation of SA and PVA was determined. Then, as the step\#2, the optimized formula was employed to evaluate the optimized conditions

\subsection{Design Expert(DOE)}

In this study, Response surface methodology (RSM) using central composite design (CCD) was employed to find the optimum formulation to prepare 3D printed SA/PVA scaffold with proper strand diameter, appropriate tensile strength, and high cell compatibility. The main parameters including $P, T$, and $V$ were evaluated upon the optimized formulation. Accordingly, the percentage of PVA and SA in bioink composition were considered as the process parameters in DOE. Three levels, including low $(-1)$, medium (0), and high (+1), were defined for PVA and SA concentration separately. According to our literature study, for PVA, the low and high levels were $1 \%$ and $12 \% \mathrm{w} / \mathrm{w}$, respectively, and for SA were $1 \%$ and $4 \%$.

According to Table 1, 13 runs were performed. Printability was measured as the response. The measured response was transferred in the software, which provided equation and relevant graphs to show the governed relation between material composition and the considered response. The main aim of DOE was to find out the most optimal condition and composition for making scaffold.

Table 1: Experimental design parameters and responses for SA/PVA electrospinning evaluation. 


\begin{tabular}{|llllll|}
\hline Runs & \multicolumn{2}{l}{ Coded runs } & Factors & Response \\
\cline { 2 - 6 } & PVA & Na.A & PVA wt.\% & Na.A wt.\% & Nanofiber producibility \\
\hline 1 & -1 & 0 & 1 & 2.5 & 1 \\
\hline 2 & -1 & 1 & 1 & 4 & 2 \\
\hline 3 & 1 & -1 & 12 & 1 & 1 \\
\hline 4 & 0 & -1 & 6.5 & 1 & 4 \\
\hline 5 & -1 & -1 & 1 & 1 & 1 \\
\hline 6 & 0 & 0 & 6.5 & 2.5 & 3 \\
\hline 7 & 0 & 1 & 6.5 & 4 & 2 \\
\hline 8 & 1 & 1 & 12 & 4 & 1 \\
\hline 9 & 0 & 0 & 6.5 & 2.5 & 3 \\
\hline 10 & 1 & 0 & 12 & 2.5 & 1 \\
\hline 11 & 0 & 0 & 6.5 & 2.5 & 3 \\
\hline 12 & 0 & 0 & 6.5 & 2.5 & 3 \\
\hline 13 & 0 & 0 & 6.5 & 2.5 & 3 \\
\hline
\end{tabular}

Table 2: Experimental design parameters and responses to study the effect of electrospinning parameters $(\mathrm{V}, \mathrm{X}$, and $\mathrm{Q})$. 


\begin{tabular}{|llllllll|}
\hline Runs & \multicolumn{2}{l}{ Coded runs } & \multicolumn{3}{l|}{ Factors } & Response \\
\cline { 2 - 4 } & $\mathbf{V}(\mathrm{kV})$ & $\mathbf{X}(\mathrm{mm})$ & $\mathbf{Q}(\mathrm{ml} / \mathrm{h})$ & $\mathbf{V}(\mathbf{k V})$ & $\mathbf{X}(\mathrm{mm})$ & $\mathbf{Q}(\mathrm{ml} / \mathrm{h})$ & Nanofiber producibility \\
\hline 1 & 1 & 0 & 0 & 1 & 12.5 & 0.55 & 3 \\
\hline 2 & 0 & 1 & 0 & 15.5 & 20 & 0.55 & 2 \\
\hline 3 & 0 & 0 & -1 & 15.5 & 12.5 & 0.1 & 4 \\
\hline 4 & 1 & -1 & 1 & 30 & 5 & 1 & 1 \\
\hline 5 & 1 & 1 & -1 & 30 & 20 & 0.1 & 4 \\
\hline 6 & 1 & -1 & -1 & 1 & 5 & 0.1 & 1 \\
\hline 7 & 0 & 0 & 0 & 15.5 & 12.5 & 0.55 & 2 \\
\hline 8 & 0 & 0 & 0 & 15.5 & 12.5 & 0.55 & 1 \\
\hline 9 & -1 & 1 & 1 & 1 & 20 & 1 & 1 \\
\hline 10 & 1 & 1 & -1 & 1 & 20 & 0.1 & 3 \\
\hline 11 & 0 & 0 & 0 & 15.5 & 12.5 & 0.55 & 1 \\
\hline 12 & 0 & -1 & 0 & 15.5 & 5 & 0.55 & 5 \\
\hline 13 & 1 & -1 & 1 & 1 & 5 & 1 & 3 \\
\hline 14 & 1 & 1 & 1 & 30 & 20 & 1 & 3 \\
\hline 15 & 1 & 0 & 0 & 30 & 12.5 & 0.55 & 3 \\
\hline 16 & 0 & 0 & 0 & 15.5 & 12.5 & 0.55 & 5 \\
\hline 17 & 0 & 0 & 0 & 15.5 & 12.5 & 0.55 & 3 \\
\hline 18 & 0 & 0 & 1 & 15.5 & 12.5 & 1 & 3 \\
\hline 19 & 1 & -1 & -1 & 30 & 5 & 0.1 & 4 \\
\hline 20 & 0 & 0 & 0 & 15.5 & 12.5 & 0.55 & 1 \\
\hline & & & & & & & \\
\hline
\end{tabular}

\subsection{Polymeric solution preparation}

In order to prepare the polymer solutions accurately, since both SA and PVA are water soluble, deionized water was used as solvent. The desired volume was considered $20 \mathrm{ml}$ for each sample. First, the required amount of each substance was weighed according to the DOE results and then transferred to a $50 \mathrm{cc}$ test tube and increased to a volume of $20 \mathrm{ml}$ using deionized water. The tube was placed on a stirrer and the resulting solution was mixed for 12 hours. The final solution was sonicated at 170 watts in an ultrasonic bath for 10 minutes. Finally, the samples were stored at refrigerator. 


\subsection{Electrospinning}

Each sample was sonicated for 10 minutes before starting the electrospinning process. Then, $5 \mathrm{cc}$ of each sample was transferred into a $10 \mathrm{cc}$ syringe. It was noted that the solution be free of any bubbles. The drums were covered by aluminum foil. The electrospinning process was investigated by changing the three parameters of voltage $(<30 \mathrm{kV})$, flow rate $(<1 \mathrm{ml} / \mathrm{h})$, and the nozzle distance $(<30 \mathrm{~cm})$ from the drum.

\subsection{Cross-linking}

Since both polymers polyvinyl alcohol and sodium alginate are water-soluble, after the fiber production process and drying, this solubility is still high, and on first contact with the aqueous medium, the fibers dissolve in water (culture medium). The cross-linking process was carried out to improve this issue. In this regard, $25 \%$ glutaraldehyde solution was used. For this purpose, the desired pieces were cut from foil and placed in a petri dish. $2 \mathrm{ml}$ of $25 \%$ glutaraldehyde solution was poured into a small container and transferred to the petri dish containing fiber pieces. The petri dish was sealed with parafilm and were placed in an incubator at $37.5^{\circ} \mathrm{C}$ for 24 hours. At the end of the course, all glutaraldehyde solution was evaporated.

\subsection{Scanning Electron Microscopy}

To measure the size distribution and surface structure of the 3D printed scaffolds, and cell attachment, scanning electron microscopy (SEM) (Philips XL30; Philips, Eindhoven, Netherlands) was carried out under a $25 \mathrm{kV}$ accelerated voltage after sputtering a gold layer with a $5 \mathrm{~nm}$ diameter on the samples. The average strand diameter was calculated using the ImageJ software (National Institute of Health, USA).

\subsection{FTIR}

To ensure the link between the SA and PVA functional groups and also the chemical bonds, specific values of each sample were prepared and analyzed by infrared spectrometer (FTIR, SHIMADZU, 8400S model Japan) with KRS-5PRISM at a 45 degree angle. The IR spectrum appeared in the wavelength range 500 to $4000 \mathrm{~cm}^{-1}$.

\subsection{Degradation}

Scaffolds were freeze-dried and then weighed to determine their initial masses. The samples were incubated in $10 \mathrm{mM}$ PBS solution in $\mathrm{pH}=7.4$ at $37 \circ \mathrm{C}$ and $5 \%$ carbon dioxide (according to the cell culture conditions) for $3,7,14$, and 21 days to obtain the degraded scaffolds. The PBS solution was taken out of the samples and then washed with deionized water two times, and then samples were freeze-dried and weighed again using a digital scale. The scaffold degradation was calculated using the equation 1 : 
$\%$ Degradation $=\frac{W_{0}-W_{t}}{W_{0}} \times 100$

$W t$ is the freeze-dried scaffold weight at a given time, and $W 0$ is the freeze-dried scaffold weight at the time zero.

\subsection{Swelling}

The primary weight of the scaffolds was measured after crosslinking. The scaffolds were then incubated in $10 \mathrm{mM}$ PBS solution in $\mathrm{pH} 7.4$ at $37 \circ \mathrm{C}$ and $5 \%$ carbon dioxide (according to the cell culture conditions). The samples' weights were measured again after $24 \mathrm{~h}$ for any mass change due to swelling. A Kimwipe was used to eliminate excess or free liquid from the scaffolds before weighing each sample. The swelling of the composite scaffolds was calculated using the equation 2 :

$$
\% \text { Swelling }=\frac{W_{t}-W_{0}}{W_{0}} \times 100
$$

\subsection{Contact Angel}

To determine and compare the hydrophilicity of different scaffolds, the water contact angle of the samples was measured. For this purpose, first the sample was placed on a flat surface and then a drop of water was dropped on it with a moving needle. The spherical image of the droplet was transmitted to the monitor by a digital camera and then the contact angle of the droplet with the web surface of the nanofibers was measured.

\subsection{Porosity}

The porosity of the scaffolds measured according to the SEM images using Image J software. In order to process the images to obtain the total porosity, the total porosity was measured as the sum of the areas between the fibers, expressed as a percentage.

\subsection{MTT}

To evaluate the cytotoxicity of the prepared scaffolds, first the electrospun scaffolds were immersed in $70 \%$ ethanol for 24 hours. After drying the scaffolds at room temperature, the scaffolds (both sides) were sterilized for one hour by exposure to UV rays. The scaffolds were then carefully placed on a plate and washed with sterile PBS. Fibroblast L929 cell line obtained from the cell bank in School of Advanced Technologies in Medicine (Shahid Beheshti University of Medical Sciences, Tehran, Iran) with a density of $2 \times 10^{3}$ per milliliter and were placed on scaffolds by drip method at a rate of 20 microliters. Next, the scaffolds were incubated for $48 \mathrm{~h}$ at $37^{\circ} \mathrm{C}$ and $5 \% \mathrm{CO}_{2}$. At the end of the period, $10 \mu \mathrm{l}$ of the MTT labeling reagent at the concentration of $0.5 \mathrm{mg} / \mathrm{ml}$ was added to each well and incubated the them for $4 \mathrm{~h}$ under 
the same conditions $\left(37^{\circ} \mathrm{C}\right.$ and $\left.5 \% \mathrm{CO}_{2}\right)$. Then, $100 \mu$ of the solubilization solution was added into each well. Left the plate for incubation at $37^{\circ} \mathrm{C}$ and $5 \% \mathrm{CO}_{2}$ overnight. The purple formazan crystals were checked and the absorbance was measured by ELISA reader.

\section{Result And Discussion}

\subsection{RSM statistical study (The effect of SA:PVA ratio and The effect of the operating parameters)}

In this research, it was tried to improve the electrospinning potential of SA by combination with PVA and also study the electrospinning main parameters $(V, Q$, and $X)$ to produce nanofibers with better quality. To aim this, As can be seen in Table 1, 13 runs have been considered according to the RSM study to find out the nanofiber producibility of each formulation of SA and PVA. Table 2, represents 20 different conditions to produce nanofibers. The DOE software provided quadratic equations as the governing relations between the percentage of ingredients and the selected response (nanofiber production) were examined via ANOVA. Table 3 summarizes the results.

The reliability of a model is usually justified via P-value, which should be lower than 0.05 to conclude that the model fitting the experimental data is valid and significant [31]. As can be seen in Table 1, the P-value was lower than 0.05 in both studies. Considering the effect of the percentage of the SA and PVA on nanofiber producibility, $P$-value was higher than 0.05 for $A$ and $B$ (as the first-order effects ), $A B$ (interaction effect) and $B^{2}$ (as the second-order effects). P-value was lower for $A^{2}$ as the second-order effect of PVA (Fig.1). Regarding the effect of operation parameters, P-value has been reported lower than 0.05 which depicts the validity and significance of the governed equation. The P-value was lower than 0.05 only for $A$ as the first-order effect, $A B$ as the interaction order, $C^{2}$ as the second-order effect. P-value was too high for $\mathrm{AC}$ and $\mathrm{BC}$ and $\mathrm{C}$.

Table 3: The governed equations and the relevant analysis of variance results

\begin{tabular}{|llllll|}
\hline Response & Final equation in terms of code factors & $\begin{array}{l}\text { P- } \\
\text { value }\end{array}$ & $\mathbf{R}^{2}$ & $\begin{array}{c}\text { Adj. } \\
\mathbf{R}^{2}\end{array}$ & AP \\
\hline $\begin{array}{l}\text { Nanofiber } \\
\text { producibility* }\end{array}$ & $\begin{array}{l}2.97-0.17 \mathrm{~A}-0.17 \mathrm{~B}-0.25 \mathrm{AB}-1.88 \mathrm{~A}^{2}+0.12 \\
\mathrm{~B}^{2}\end{array}$ & 0.01 & 0.83 & 0.72 & 6.83 \\
\hline $\begin{array}{l}\text { Nanofiber } \\
\text { producibility** }\end{array}$ & $\begin{array}{l}3.4+0.9 \mathrm{~A}+0.5 \mathrm{~B}-0.1 \mathrm{C}+0.75 \mathrm{AB}-0.5 \mathrm{~A}^{2}+ \\
0.5 \mathrm{~B}^{2}-1.5 \mathrm{C}^{2}\end{array}$ & 0.016 & 0.79 & 0.61 & 6.3 \\
\hline
\end{tabular}

${ }^{*} A: P V A-B: S A, * * A: V, B: X, C: Q$

The reliability of a fitted model is specified by the determinant coefficient $\left(R^{2}\right)$ and Adj. $R^{2}$ as its adjusted form. The validity of the model can be approved if $R^{2} \geq 0.6$ [32]. both models showed $R^{2}$ equal 0.83 and 0.79 and had a reasonable agreement with adj. $R^{2}$ indicating that the models are capable to analyze and 
predict the response over the change in the process parameters. Adequate precision (AP) compares the range of the predicted values at the design points to the average prediction error, where a ratio higher than 4 is desirable [33]. As Table 3 depicts, in both models, AP values reported higher than 4 , showing that there was a good agreement between the predicted and experimental values including most of the responses.

Fig.1 shows the relation of response with the effect of the SA and PVA combination. Based on the contour results, a higher number of their combination fail in nanofiber production and the likelihood of nanofiber producibility was too low. According to the experimental results, the only SA:PVA ratio that showed spinnability was 1:6.5. In other cases, no nanofiber was produced due to high or low viscosity and lack of enough surface tension. SA did not show spinnability when employed lonely. The reason might be related to the limited solubility and high viscosity of this natural polyelectrolytic polymer. Previous studies reported that the combination of SA with other polymers increases the spinnability of SA $[34,35]$. Due to the formed hydrogen bonds between the SA and other polymers such as PCL, the repulsive force between the polyionic molecules is notably reduced to boost chain fusion, which finally leads to the nanofibers production [36]. For instance, Gong and his colleagues produced SA-based nanofibers by employing polyethylene oxide (PEO) [33]. Lu et al. [37] studied the electrospinning ability of SA in combination with PEO at a concentration of 1 to $4 \%$. They showed that only $3 \%$ of PEO resulted in smooth and uniform nanofibers. It was reported that the final viscosity plays a vital role in spinnability [38]. In some cases, addition of Surfactants such as triton-X100 can improve the viscosity and also the spinnability [39]. Based on the obtained governed equation in Table 3, it seems that adition of PVA in each concentration did not guarantee the spinnability of SA and only the $6.5 \%$ of PVA combined with $1 \%$ of SA resulted in nanofibers. The mentioned ratio was considered as the optimized SA:PVA ratio. To analyze the nanofiber and also the effect of process parameters on the quality of the synthesized nanofibers, this ratio was used as the main formulation for the rest of the study. Other ratios did not result in nanofiber production under any adjustment of operating parameters including voltage (0-30 kV), the working distance $(5-20 \mathrm{~cm})$, and flow rate $(0.1-1 \mu \mathrm{l} / \mathrm{h})$.

The effect of $\mathrm{X}$ and $\mathrm{V}$ : As can be seen in Fig.2-A, at constant Q, low V affects the nanofiber production negatively. To produce nanofibers at low $\mathrm{V}$, it is necessary to decrease the working distance (lower $\mathrm{X}$ ). However nanofiber production at a higher voltage and working distance is more possible compared with lower levels.

The effect of $\mathbf{V}$ and Q: At constant $X$, Fig. 2-B shows that the likelihood of nanofiber production can be increased by optimization of the Q. Fig.2-B also depicts that by enhancing $\mathrm{V}$, the Q must be adjusted at an average flow rate which means in higher or lower $\mathrm{Q}$ (set in range) spinnability decreases. However, the distance needs to be adjusted (Fig.2-A).

The effect of $Q$ and X: Fig.2-C illustrates that adjusting $Q$ in a high or low rate (at constant $V$ ) cannot result in nanofiber production possibility. The appropriate $Q$ seemed to be set around $0.5 \mathrm{ml} / \mathrm{h}$ but in high working distances. Under this condition, spinnability is more improved. 
In general, $\mathrm{V}, \mathrm{Q}$, and $\mathrm{X}$ need to be adjusted to increase spinnability. Based on the results the central points for $V, Q$, and $X$ seemed to be the apropriate levels. The applied voltage is a critical factor in electrospinning for spinnability. This is because nanofiber production only happens when the applied voltage exceeds the threshold voltage [40]. In the case of voltage, levels equal or above $15.5 \mathrm{kV}$ showed better improvement. In similar research, the voltage between $12.5-24 \mathrm{kV}$ was reported as appropriate $\mathrm{V}$ for nanofiber production of SA/PEO. It was reported that too high or too low $V$ fails spinnability [41]. According to the previous reports, increasing the applied voltage increases the electrostatic force of the polymer solution, which is visible in jet traction, and ultimately reduces the length of the nanofibers [42]. It has also been reported that changing the applied voltage changes the quality of the nanofibers, thereby changes the diameter and morphology of the nanofibers [43]. Reneker et al. [44] stated that enhancement in the applied voltage has no effect on the fiber diameter of PEO. However, in 2005 Zhang and his colleagues reported obtaining larger-diameter nanofibers higher voltages must be applied because it causes more polymer ejection [45]. Interestingly, Other scientists have reported that an increase in the applied voltage decreases the nanofiber diameter. Furthermore, it was observed that at higher applied voltages, bead formation was obtained on the fibers $[42,46]$.

Another parameter that affects the control of morphology and diameter of nanofibers is the distance of the nozzle from the collector. To prevent evaporation of the polymer solution before the fiber reaches the collector, it is necessary to optimize the distance [47]. Therefore, in the electrospinning method, an optimized distance is required to fibers reach the collector and prevent solvent evaporation. Based on the results of our study, this distance depends entirely on the applied voltage and the flow rate. Longer distances have been reported to produce thinner fibers [48] but this claim is true when increasing the distance does not have a negative effect on fiber formation and power outages [49]. Also, beads will appear when they are too close or too far $[43,50]$. In a study, it was reported that increasing the working distance caused an increase in diameter [51]. Interestingly, because the fibers need to be cooled to achieve uniform fibers and to prevent fiber fusion, shorter collector distances can increase the likelihood of fiber fusion at the junction.

Polymer flow rate indicates the flow rate of the polymer solution per unit time, which is known as another factor affecting the quality of fibers. It has been reported that increasing the flow rate causes more polymeric material to come out of the nozzle, which leads to the production of coarser fibers. Low flow rates are essential for the production of good quality fibers with uniform diameters [52]. It has been predicted that nanofiber diameter decreases due to increased charge density at low rates [42]. It was also reported that with increasing flow rate, there is a continuous increase in nanofiber diameter [44]. It is notable that an excessive increase in flow rate not only enhances the integration of nanofibers but also creates a bead in the fiber structure because not enough time is provided for solvent evaporation.

Experimental results showed that only the following runs were succeeded in electrospinning: 2-3-5-7-8-1112-14-15-16-17-18-20. Amongst them, run numbers of 7-8-11-16-17-20 were considered as the repeated runs to evaluate the validity of the experiment and monitoring the errors from the operator. The appearance evaluation and also the SEM analysis of these groups (data not provided) were the same and 
run 8 was considered as the representative of these runs. Hence, the only groups employed in the next analysis were 3-5-7-8-12-14-15-18. In the rest, they are named Scaffold 3, Scaffold 5, ..., Scaffold 18.

\subsection{Morphology and physical evaluation of the nominated scaffolds.}

Fig. 3 and Fig. 4 show the SEM images of the scaffolds with two magnifications and fiber diameter distribution. The porosity and the fiber diameters are also reported in Table 4. As can be seen, scaffolds depicted differences in nanofiber density, uniform distribution, nanofiber diameter, and the quality of electrospinning with fewer or no beads. Fig. 3 shows that scaffolds 3 and 12 did not have uniform nanofibers in size distribution and quality. The voltage was equal for both scaffolds but they were different in distance and flow rate. The scaffolds 2, 5, and 7 although had uniform nanofibers but showed a low density of nanofibers The reason can be attributed to the disproportion of flow rate to distance. Low flow rate $(<0.55 \mu \mathrm{l} / \mathrm{h})$ towards the voltage $(>15 \mathrm{kV})$ can be considered as the main reason for low density. This is while the scaffolds 14,15 , and 18 illustrated the best results in density, uniform nanofibers and smooth fibers. According to Table 4, the lowest and highest porosity belonged the scaffold $14\left(521 \mathrm{~nm}^{2}\right)$ and $3\left(1404 \mathrm{~nm}^{2}\right)$ respectively. Scaffolds 2 and 7 also had high porosity equal to 1004 and $1205 \mathrm{~nm}^{2}$ respectively. Considering the size distribution of nanofiber, Table 4 also shows that the thin nanofiber belonged to the scaffold 12 and $15(140-170 \mathrm{~nm})$ while the scaffold 3 and 7 owned the thick nanofibers ( $300 \pm 5 \mathrm{~nm}$ respectively). Scaffold s $2,5,14$, and 18 showed nanofibers in the range of 220-240 $\mathrm{nm}$. It can be hypothesized that applying higher voltage between 15.5-30 kV, adjusting the distance between $12.5-20 \mathrm{~cm}$, and providing the flow rate at 0.5-1 $\mu \mathrm{l} / \mathrm{h}$ resulted in appropriate nanofibers. The results were in agreement with previous studies. Hu and his colleagues produced SA/PEO nanofibers with 120-160 nm in diameters under 12, 18 and $24 \mathrm{kV}$ [41]. The little difference may be attributed to the process parameters. In another study, the SA/PVA nanofibers were produced with 140-350 nm diameter [53]. Table 4 also depicts the results from the contact angle analysis which due to the high hydrophilic feature of both SA and PVA, the reported contact angle for all scaffolds was lower than $5 \rrbracket$ meaning that the scaffolds are extremely hydrophlilic.

Table 4: The physical properties of the elected scaffolds. 


\begin{tabular}{|llll|}
\hline Scaffold & Porosity Area $\left(\mathrm{nm}^{2}\right)$ & Fiber mean diameter $(\mathrm{nm})$ & Contact angle \\
\hline scaffold 2 & 1004.668 & 222.6 & $<5 \rrbracket$ \\
\hline scaffold 3 & 1404.154 & 296.5 & $<5 \rrbracket$ \\
\hline scaffold 5 & 791.831 & 239.5 & $<5 \rrbracket$ \\
\hline scaffold 7 & 1205.018 & 307 & $<5 \rrbracket$ \\
\hline scaffold 12 & 556.001 & 137 & $<5 \rrbracket$ \\
\hline scaffold 14 & 521.317 & 210 & $<5 \rrbracket$ \\
\hline scaffold 15 & 619.965 & 166 & $<5 \rrbracket$ \\
\hline scaffold 18 & 829.567 & 227 & $<$ \\
\hline
\end{tabular}

According to the results from the morphology analysis and quality evaluation of the synthesized nanofibers, Scaffold 14, 15 and 18 were nominated for more analysis. These scaffolds revealed appropriate density, smooth nanofibers, uniform size distribution and suitable porosity. In the rest of the study, the scaffolds were first crosslinked under $25 \%$ glutaraldehyde vapor and then were evaluated.

\section{3 chemical structure}

Fig. 5 shows the FTIR spectra of the three nominated crosslinked scaffolds (Scaffold14, 15, and 18). Since the elected SA:PVA ratio has been the same for all scaffolds, thereby one of the scaffolds has been nominated as the control group (without crosslinking). The SA/PVA electrospun scaffolds showed similar trends. The characteristic bands for SA were in the range of 3600 and $1500 \mathrm{~cm}^{-1}$. The characteristic bands of the scaffolds spectrum (Fig.5) are as follows. Appeared peaks at $3291 \mathrm{~cm}^{-1}$ and $2913 \mathrm{~cm}^{-1}$ belong to $\mathrm{O}-\mathrm{H}$ stretching (hydroxyl group) and $\mathrm{C}-\mathrm{H}$ stretching vibration respectively [54]. Appeared peak at $1088 \mathrm{~cm}^{-1}$ belongs $\mathrm{CN}$ group. The appeared sharp peak at $1717 \mathrm{~cm}^{-1}$ is attributed to the carboxylate group [55]. Comparing with the control group, a shoulder appeared before the peak at $1087 \mathrm{~cm}^{-1}$ and expanded the appeared peak. Besides, a new peak appeared at $943 \mathrm{~cm}^{-1}$ belongs to the $\mathrm{CH}_{2}$ rocking [56] which probably is attributed to the process of cross-linking by glutaraldehyde [57]. The spectra of the scaffolds were similar to that of pure PVA [58] which the reason is the high PVA content in all scaffolds (SA:PVA; 1:6.5). the appeared peak at $843 \mathrm{~cm}^{-1}$ is attributed to the $\mathrm{C}-\mathrm{C}$ stretching [59].

\subsection{Degradation}

The degree of destruction of each scaffold was also measured by observing a change in the mass of the samples after immersion in PBS over time. Fig. 6 depicts the degradation behavior of the scaffolds during incubation. Scaffolds 14,15 and 18 showed $28 \%, 33 \%$, and $39 \%$ of degradation after 21 days of incubation in PBS under similar patterns. The low and high rate of degradation belonged to Scaffolds 14 and 18 respectively. Various reasons can influence degradation behavior. Although the scaffolds 
experienced the same conditions in the cross-linking process there is a likelihood of variance in the level of cross-linking. However, the results from the FTIR did not show significant differences in cross-linking and chemical structures. Ki-Taek Lim et al. [60] reported that cross-linker and the time of cross-linking could affect the degradation process. By the way, the changes in the electrospinning parameters lead to a difference in density and diameter of nanofibers. The more nanofibers, the more chemical band between the polymeric chains [61]. Based on the results from porosity and SEM, it was hypothesized that the higher porosity can be imagined as the vital parameter in the rate of degradation behavior. The higher porosity resulted in low density and also cross-linking [62].

\subsection{Swelling}

The swelling behavior of the scaffold demonstrates the ability of nutrients and wastes to exchange between the environment and cells embedded in the scaffold to produce artificial tissue. Swelling efficiency directly refers to the ability to hydrate and stabilize within the biological systems $[63,64]$. All scaffolds were incubated in PBS to evaluate the rate of water absorption over time.

The behavior of scaffolds in water absorption and swelling showed similar trends (Fig. 7). Scaffolds 14, 15 , and 18 revealed $250 \%, 260 \%$, and $160 \%$ swelling respectively after $24 \mathrm{~h}$ of incubation. According to the data, Scaffold 14 and 15 showed the highest but closed water absorption in contrast with another scaffold 18 . The reason may be attributed to the high porosity of the scaffold 18 which means the low density of nanofibers [65]. It has been reported that the swelling potential of the scaffolds can be affected by the degree of crosslinking, amorphous regions, and level of hydroxyl groups [66-68]. According to the FTIR results, due to no significant difference in the results, it seems that the degree of cross-linking did not affect swelling notably. Comparing all scaffolds, they are made of the same SA/PVA combination but were different in operating parameters. Nanofiber diameter is one of the vital parameters of electrospun scaffolds and is affected by surface tension, solution viscosity, working distance, flow rate, crystallization characteristics and applied voltage [69]. Nanofiber diameter also can affect the porosity of the scaffold, thereby it could be concluded that porosity has been affected by operating conditions [12]. This effect may appear in the density of nanofibers per $1 \mathrm{~cm}^{2}$ and the diameter of nanofibers (166-227 nm). Furthermore, it is hypothesized that thick nanofibers will adsorb a higher amount of water than thin nanofibers. So a dense scaffold is predicted to be degraded late.

\subsection{Tensile Strength}

The mechanical behavior is a critical factor in studying the mechanical behavior of a scaffold. The tensile strength $(\mathrm{MPa})$ of the scaffolds was measured by determining the strain-stress curve and measurement of the elastic modulus (EM) of each scaffold Fig.6. Scaffolds 14 and 15 had closed trends (Fig.8-A) indicating no significant difference $(P>0.05)$ in the viewpoint of EM compared with the scaffold 18 (Fig8-B). However, scaffold 15 revealed higher EM compared with Scaffold 14 and 18. Scaffold 18 showed the lowest EM $(P<0.05)(F i g .8-B)$. It has been approved that the porosity has an adverse effect on mechanical behavior [70]. It was also reported that cross-linking can be the main factor affecting the 
mechanical behavior of scaffolds [71]. Hence, according to Table 4, scaffold 18 owned higher porosity, which low EM can be predicted about it. In the viewpoint of nanofiber diameters, interestingly, reduction in nanofiber diameters caused an enhancement in mechanical response including Young's modulus (EM) and tensile strength which the surface confinement of chains on the distribution of stresses in the fibers was considered as the main reason [69]. Smooth nanofibers with uniform distribution of diameter result in the densely packed scaffold with a high-molecular orientation that leads to higher resistance to the axial tensile forces. In this regard, it was reasonable that scaffold 15 reveals higher EM.

\subsection{MTT}

This study aimed to fabricate a SA/PVA electrospun scaffold in skin TE; thereby, it was necessary to assess the cytotoxicity and biocompatibility of the scaffolds. The MTT assay was determined for suitability of scaffolds for Fibroblast L929 cell line viability, as shown in Fig. 9. According to the cytotoxic assay, there was no significant difference in viability $(P>0.05)$ between the scaffolds compared with the control group ( $>75 \%$ ), which means that all three scaffolds are suitable for cell culture and skin TE purposes. Based on the results from swelling and porosity assessments, the diversity in porosity and nanofiber diameters did not make a significant difference in the cell viability of the scaffolds. On the other hand, based on cell growth as well as cell concentration in each scaffold, it can be claimed that all scaffolds showed good cell adhesion compared to other scaffolds. Previous studies reported the biocompatibility of SA, PVA and SA/PVA. For instance, wei and You-Lo fabricated SA/PVA hybrid fibers (40\% PVA and 60 SA) under physical crosslinking. They reported that the nanofibers were biocompatible and showed no cytotoxicity [53]. Pure SA also showed higher biocompatibility and in spite of it higher potential in TE, still, no cytotoxicity has been reported for this Polysaccharide [72]. Regarding PVA, biocompatibility results from the previous studies demonstrated that pure PVA was slightly toxin and irritant to the surrounding tissues [73]. However, it was reported that PVA biocompatibility can be improved when integrated with other biocompatible polymers including collagen, SA, Gellatin, and so on [74].

\section{Conclusion}

The spinnability of Sodium alginate, a biodegradable and biocompatible polymer, was first assessed in combination with the different percentages of PVA. Then the optimized SA:PVA ratio was nominated to optimize the processing parameters including voltage, working distance, and flow rate. SA inherently is not spinnable, thereby combination with other spinnable polymers improves its potential in nanofiber production. Different percentages of PVA were studied and only the 6.5 PVA depicted good spinnability. The spinnability of the optimized ratio could be controlled with the variation of the applied voltage, flow rate, and working distance. some conditions did not result in nanofibers. The results revealed the Uniform and homogeneous nanofibers with the regular size distribution with narrow diameter ( $<170 \mathrm{~nm}$ ) were obtained at $15-30 \mathrm{kV}, 0.55-1 \mu \mathrm{l} / \mathrm{h}$, and $12.5-20 \mathrm{~cm}$. the fabricated scaffolds under these conditions revealed good physical, chemical, mechanical and biological features. 


\section{Declarations}

\section{Acknowledgment}

This research did not receive any specific grant from funding agencies in the public, commercial, or not-for-profit sectors

Funding: NO funding

Conflict of Interest: All authors declare no financial/commercial conflicts of interest.

Availability of data and material: All data and material are available

Code availability: Not applicable

Additional declarations for articles in life science journals that report the results of studies involving humans and/or animals: Not applicable

Ethics approval: Since we do not receive any funding for this work, thank you for giving us a discount for APC charging.

Consent to participate: Not applicable

Conset for publication: We confirm this.

\section{References}

1. Y. Ikada, Challenges in tissue engineering, Journal of the Royal Society Interface 3(10) (2006) 589601.

2. R. Sánchez-Sánchez, A. Brena-Molina, V. Martínez-López, Y. Melgarejo-Ramírez, L. Tamay de Dios, R. Gómez-García, M.d.L. Reyes-Frías, L. Rodríguez-Rodríguez, D. Garciadiego-Cázares, H. Lugo-Martínez, C. Ibarra, M.E. Martínez-Pardo, C. Velasquillo-Martínez, Generation of Two Biological Wound Dressings as a Potential Delivery System of Human Adipose-Derived Mesenchymal Stem Cells, ASAIO Journal 61(6) (2015).

3. S.-H. Shin, O. Purevdorj, O. Castano, J.A. Planell, H.-W. Kim, A short review: Recent advances in electrospinning for bone tissue regeneration, Journal of tissue engineering 3(1) (2012) 2041731412443530.

4. H. Bannasch, M. Föhn, T. Unterberg, F. Knam, B. Weyand, G. Stark, Skin tissue engineering, Der Chirurg; Zeitschrift fur Alle Gebiete der Operativen Medizen 74(9) (2003) 802-807.

5. F. Groeber, M. Holeiter, M. Hampel, S. Hinderer, K. Schenke-Layland, Skin tissue engineering-in vivo and in vitro applications, Advanced drug delivery reviews 63(4-5) (2011) 352-366.

6. S.G. Priya, H. Jungvid, A. Kumar, Skin tissue engineering for tissue repair and regeneration, Tissue Engineering Part B: Reviews 14(1) (2008) 105-118. 
7. J. Mansbridge, Skin tissue engineering, Journal of Biomaterials Science, Polymer Edition 19(8) (2008) 955-968.

8. P. Ranjbarvan, M. Mahmoudifard, M. Kehtari, A. Babaie, S. Hamedi, S. Mirzaei, M. Soleimani, S. Hosseinzadeh, Natural Compounds for Skin Tissue Engineering by Electrospinning of Nylon-Beta Vulgaris, ASAIO Journal 64(2) (2018).

9. M. Chen, M. Przyborowski, F. Berthiaume, Stem cells for skin tissue engineering and wound healing, Critical Reviews ${ }^{\mathrm{TM}}$ in Biomedical Engineering 37(4-5) (2009).

10. A.W.C. Chua, Y.C. Khoo, B.K. Tan, K.C. Tan, C.L. Foo, S.J. Chong, Skin tissue engineering advances in severe burns: review and therapeutic applications, Burns \& trauma 4 (2016) 1-14.

11. L. Brasile, P. Glowacki, B.M. Stubenitsky, Bioengineered Skin Allografts: A New Method To Prevent Humoral Response, ASAIO Journal 57(3) (2011).

12. X. Zhu, W. Cui, X. Li, Y. Jin, Electrospun fibrous mats with high porosity as potential scaffolds for skin tissue engineering, Biomacromolecules 9(7) (2008) 1795-1801.

13. S. Agarwal, J.H. Wendorff, A. Greiner, Progress in the field of electrospinning for tissue engineering applications, Advanced Materials 21(32-33) (2009) 3343-3351.

14. V. Mironov, Toward Human Organ Printing: Charleston Bioprinting Symposium, ASAIO Journal 52(6) (2006).

15. A. Keirouz, M. Chung, J. Kwon, G. Fortunato, N. Radacsi, 2D and 3D electrospinning technologies for the fabrication of nanofibrous scaffolds for skin tissue engineering: A review, Wiley Interdisciplinary Reviews: Nanomedicine and Nanobiotechnology 12(4) (2020) e1626.

16. Y.R. Park, H.W. Ju, J.M. Lee, D.-K. Kim, O.J. Lee, B.M. Moon, H.J. Park, J.Y. Jeong, Y.K. Yeon, C.H. Park, Three-dimensional electrospun silk-fibroin nanofiber for skin tissue engineering, International journal of biological macromolecules 93 (2016) 1567-1574.

17. D. Sundaramurthi, U.M. Krishnan, S. Sethuraman, Electrospun nanofibers as scaffolds for skin tissue engineering, Polymer Reviews 54(2) (2014) 348-376.

18. K. Ghosal, A. Manakhov, L. Zajičková, S. Thomas, Structural and surface compatibility study of modified electrospun poly ( $\varepsilon$-caprolactone)(PCL) composites for skin tissue engineering, Aaps Pharmscitech 18(1) (2017) 72-81.

19. C. Ru, F. Wang, M. Pang, L. Sun, R. Chen, Y. Sun, Suspended, shrinkage-free, electrospun PLGA nanofibrous scaffold for skin tissue engineering, ACS applied materials \& interfaces 7(20) (2015) $10872-10877$.

20. M.A. Teixeira, M.T.P. Amorim, H.P. Felgueiras, Poly (vinyl alcohol)-based nanofibrous electrospun scaffolds for tissue engineering applications, Polymers 12(1) (2020) 7.

21. X. Liu, L.H. Nielsen, S.N. Kłodzińska, H.M. Nielsen, H. Qu, L.P. Christensen, J. Rantanen, M. Yang, Ciprofloxacin-loaded sodium alginate/poly (lactic-co-glycolic acid) electrospun fibrous mats for wound healing, European Journal of Pharmaceutics and Biopharmaceutics 123 (2018) 42-49. 
22. M. Bouhlouli, M. Pourhadi, F. Karami, Z. Talebi, J. Ranjbari, A. Khojasteh, Applications of Bacterial Cellulose as a Natural Polymer in Tissue Engineering, ASAIO Journal Online First (9000).

23. I. Yousefi, M. Pakravan, H. Rahimi, A. Bahador, Z. Farshadzadeh, I. Haririan, An investigation of electrospun Henna leaves extract-loaded chitosan based nanofibrous mats for skin tissue engineering, Materials Science and Engineering: C 75 (2017) 433-444.

24. J.J. Vázquez, E.S.M. Martínez, Collagen and elastin scaffold by electrospinning for skin tissue engineering applications, Journal of Materials Research 34(16) (2019) 2819-2827.

25. Q.P. Pham, U. Sharma, A.G. Mikos, Electrospinning of polymeric nanofibers for tissue engineering applications: a review, Tissue engineering 12(5) (2006) 1197-1211.

26. G. Manikandan, M. Yuvashree, A. Sangeetha, K. Bhuvana, S.K. Nayak, Liver tissue regeneration using nano silver impregnated sodium alginate/PVA composite nanofibres, SciMedicine Journal 2(1) (2020) 16-21.

27. N.A. Pattanashetti, D.D. Achari, A.I. Torvi, R.V. Doddamani, M.Y. Kariduraganavar, Development of multilayered nanofibrous scaffolds with PCL and PVA: NaAlg using electrospinning technique for bone tissue regeneration, Materialia 12 (2020) 100826.

28. D. Coelho, A. Sampaio, C.J. Silva, H.P. Felgueiras, M.T.P. Amorim, A. Zille, Antibacterial electrospun poly (vinyl alcohol)/enzymatic synthesized poly (catechol) nanofibrous midlayer membrane for ultrafiltration, ACS applied materials \& interfaces 9(38) (2017) 33107-33118.

29. S.N. Alhosseini, F. Moztarzadeh, M. Mozafari, S. Asgari, M. Dodel, A. Samadikuchaksaraei, S. Kargozar, N. Jalali, Synthesis and characterization of electrospun polyvinyl alcohol nanofibrous scaffolds modified by blending with chitosan for neural tissue engineering, International journal of nanomedicine 7 (2012) 25.

30. K. Vig, A. Chaudhari, S. Tripathi, S. Dixit, R. Sahu, S. Pillai, V.A. Dennis, S.R. Singh, Advances in skin regeneration using tissue engineering, International journal of molecular sciences 18(4) (2017) 789.

31. R. Ghelich, M.R. Jahannama, H. Abdizadeh, F.S. Torknik, M.R. Vaezi, Central composite design (CCD)Response surface methodology (RSM) of effective electrospinning parameters on PVP-B-Hf hybrid nanofibrous composites for synthesis of HfB2-based composite nanofibers, Composites Part B: Engineering 166 (2019) 527-541.

32. L. Sasikala, R. Rathinamoorthy, B. Dhurai, Optimization of process conditions for chitosan-manuka honey film as wound contact layer for wound dressings, Wound medicine 23 (2018) 11-21.

33. M. Ahmadipourroudposht, E. Fallahiarezoudar, N.M. Yusof, A. Idris, Application of response surface methodology in optimization of electrospinning process to fabricate (ferrofluid/polyvinyl alcohol) magnetic nanofibers, Materials Science and Engineering: C 50 (2015) 234-241.

34. S. Safi, M. Morshed, S. Hosseini Ravandi, M. Ghiaci, Study of electrospinning of sodium alginate, blended solutions of sodium alginate/poly (vinyl alcohol) and sodium alginate/poly (ethylene oxide), Journal of applied polymer science 104(5) (2007) 3245-3255.

35. H. Nie, A. He, W. Wu, J. Zheng, S. Xu, J. Li, C.C. Han, Effect of poly (ethylene oxide) with different molecular weights on the electrospinnability of sodium alginate, Polymer 50(20) (2009) 4926-4934. 
36. W. Li, Y. Guan, H. Li, P. Yu, H. Luo, C. Lu, Preparation of drug-loaded polyvinyl alcohol-sodium alginate nanofiber by electrospinning, Chinese Pharmaceutical Journal 48 (2013) 980-985.

37. J.-W. Lu, Y.-L. Zhu, Z.-X. Guo, P. Hu, J. Yu, Electrospinning of sodium alginate with poly (ethylene oxide), Polymer 47(23) (2006) 8026-8031.

38. N. Bhattarai, M. Zhang, Controlled synthesis and structural stability of alginate-based nanofibers, Nanotechnology 18(45) (2007) 455601.

39. C.A. Bonino, M.D. Krebs, C.D. Saquing, S.I. Jeong, K.L. Shearer, E. Alsberg, S.A. Khan, Electrospinning alginate-based nanofibers: From blends to crosslinked low molecular weight alginate-only systems, Carbohydrate Polymers 85(1) (2011) 111-119.

40. Y. Bagbi, A. Pandey, P.R. Solanki, Chapter 10 - Electrospun Nanofibrous Filtration Membranes for Heavy Metals and Dye Removal, in: S. Thomas, D. Pasquini, S.-Y. Leu, D.A. Gopakumar (Eds.), Nanoscale Materials in Water Purification, Elsevier2019, pp. 275-288.

41. C. Hu, R.H. Gong, F.L. Zhou, Electrospun Sodium Alginate/Polyethylene Oxide Fibers and Nanocoated Yarns, International Journal of Polymer Science 2015 (2015) 126041.

42. V. Beachley, X. Wen, Effect of electrospinning parameters on the nanofiber diameter and length, Materials Science and Engineering: C 29(3) (2009) 663-668.

43. J. Venugopal, S. Ramakrishna, Applications of polymer nanofibers in biomedicine and biotechnology, Applied biochemistry and biotechnology 125(3) (2005) 147-157.

44. D.H. Reneker, I. Chun, Nanometre diameter fibres of polymer, produced by electrospinning, Nanotechnology 7(3) (1996) 216.

45. C. Zhang, X. Yuan, L. Wu, Y. Han, J. Sheng, Study on morphology of electrospun poly (vinyl alcohol) mats, European polymer journal 41(3) (2005) 423-432.

46. M.M. Demir, I. Yilgor, E. Yilgor, B. Erman, Electrospinning of polyurethane fibers, Polymer 43(11) (2002) 3303-3309.

47. R. Nayak, R. Padhye, L. Arnold, 2 - Melt-electrospinning of nanofibers, in: M. Afshari (Ed.), Electrospun Nanofibers, Woodhead Publishing2017, pp. 11-40.

48. J. Doshi, D.H. Reneker, Electrospinning process and applications of electrospun fibers, Journal of electrostatics 35(2-3) (1995) 151-160.

49. N. Ogata, S. Yamaguchi, N. Shimada, G. Lu, T. Iwata, K. Nakane, T. Ogihara, Poly (lactide) nanofibers produced by a melt-electrospinning system with a laser melting device, Journal of applied polymer science 104(3) (2007) 1640-1645.

50. Q. Yang, Z. Li, Y. Hong, Y. Zhao, S. Qiu, C. Wang, Y. Wei, Influence of solvents on the formation of ultrathin uniform poly (vinyl pyrrolidone) nanofibers with electrospinning, Journal of Polymer Science Part B: Polymer Physics 42(20) (2004) 3721-3726.

51. R. Deng, Y. Liu, Y. Ding, P. Xie, L. Luo, W. Yang, Melt electrospinning of low-density polyethylene having a low-melt flow index, Journal of Applied Polymer Science 114(1) (2009) 166-175. 
52. J.A. Matthews, G.E. Wnek, D.G. Simpson, G.L. Bowlin, Electrospinning of collagen nanofibers, Biomacromolecules 3(2) (2002) 232-238.

53. W. Shen, Y.-L. Hsieh, Biocompatible sodium alginate fibers by aqueous processing and physical crosslinking, Carbohydrate Polymers 102 (2014) 893-900.

54. R. Omidinia, S. Nouri Khorasani, M. Pezeshki-Modaress, A. Fazel Anvari-Yazdi, Effects of pH on Polyvinyl alcohol/Sodium Alginate Electrospun nanofibers morphology for Biomedical applications, 2013.

55. H. Susanto, A.M. Samsudin, M. Faz, M. Rani, Impact of post-treatment on the characteristics of electrospun poly (vinyl alcohol)/chitosan nanofibers, AIP Conference Proceedings, AIP Publishing LLC, 2016, p. 020087.

56. N.J. Vickers, Animal communication: when i'm calling you, will you answer too?, Current biology 27(14) (2017) R713-R715.

57. X. Zhang, K. Tang, X. Zheng, Electrospinning and crosslinking of COL/PVA nanofiber-microsphere containing salicylic acid for drug delivery, Journal of Bionic Engineering 13(1) (2016) 143-149.

58. I. Deleanu, A. Stoica, S. M, L. Dobre, T. Dobre, S. Jinga, C. Tardei, Potassium sorbate release from poly(vinyl alcohol)-bacterial cellulose films, Chemical Papers 66 (2012) 138-143.

59. Y. Liu, L.M. Geever, J.E. Kennedy, C.L. Higginbotham, P.A. Cahill, G.B. McGuinness, Thermal behavior and mechanical properties of physically crosslinked PVA/Gelatin hydrogels, Journal of the mechanical behavior of biomedical materials 3(2) (2010) 203-209.

60. S.D. Dutta, J. Hexiu, D.K. Patel, K. Ganguly, K.-T. Lim, 3D-printed bioactive and biodegradable hydrogel scaffolds of alginate/gelatin/cellulose nanocrystals for tissue engineering, International Journal of Biological Macromolecules (2020).

61. N. Hiraishi, J.Y. Yau, R.J. Loushine, S.R. Armstrong, R.N. Weller, N.M. King, D.H. Pashley, F.R. Tay, Susceptibility of a polycaprolactone-based root canal-filling material to degradation. III. turbidimetric evaluation of enzymatic hydrolysis, Journal of endodontics 33(8) (2007) 952-956.

62. V.A. Reyna-Urrutia, V. Mata-Haro, J.V. Cauich-Rodriguez, W.A. Herrera-Kao, J.M. Cervantes-Uc, Effect of two crosslinking methods on the physicochemical and biological properties of the collagen-chitosan scaffolds, European Polymer Journal 117 (2019) 424-433.

63. D. Chawla, T. Kaur, A. Joshi, N. Singh, 3D bioprinted alginate-gelatin based scaffolds for soft tissue engineering, International Journal of Biological Macromolecules 144 (2020) 560-567.

64. W. Xu, B.Z. Molino, F. Cheng, P.J. Molino, Z. Yue, D. Su, X. Wang, S. Willför, C. Xu, G.G. Wallace, On Low-Concentration Inks Formulated by Nanocellulose Assisted with Gelatin Methacrylate (GelMA) for 3D Printing toward Wound Healing Application, ACS Applied Materials \& Interfaces 11(9) (2019) 8838-8848.

65. J. Kucinska-Lipka, M. Marzec, I. Gubanska, H. Janik, Porosity and swelling properties of novel polyurethane-ascorbic acid scaffolds prepared by different procedures for potential use in bone tissue engineering, Journal of Elastomers \& Plastics 49(5) (2017) 440-456. 
66. H.S. Mansur, C.M. Sadahira, A.N. Souza, A.A. Mansur, FTIR spectroscopy characterization of poly (vinyl alcohol) hydrogel with different hydrolysis degree and chemically crosslinked with glutaraldehyde, Materials Science and Engineering: C 28(4) (2008) 539-548.

67. J. Zhu, R.E. Marchant, Design properties of hydrogel tissue-engineering scaffolds, Expert review of medical devices 8(5) (2011) 607-626.

68. R.M. Felfel, M.J. Gideon-Adeniyi, K.M.Z. Hossain, G.A. Roberts, D.M. Grant, Structural, mechanical and swelling characteristics of 3D scaffolds from chitosan-agarose blends, Carbohydrate polymers 204 (2019) 59-67.

69. S. Ojha, 10 - Structure-property relationship of electrospun fibers, in: M. Afshari (Ed.), Electrospun Nanofibers, Woodhead Publishing2017, pp. 239-253.

70. D.A. Shimko, V.F. Shimko, E.A. Sander, K.F. Dickson, E.A. Nauman, Effect of porosity on the fluid flow characteristics and mechanical properties of tantalum scaffolds, Journal of Biomedical Materials Research Part B: Applied Biomaterials: An Official Journal of The Society for Biomaterials, The Japanese Society for Biomaterials, and The Australian Society for Biomaterials and the Korean Society for Biomaterials 73(2) (2005) 315-324.

71. S. Naghieh, M.R. Karamooz-Ravari, M. Sarker, E. Karki, X. Chen, Influence of crosslinking on the mechanical behavior of 3D printed alginate scaffolds: Experimental and numerical approaches, Journal of the mechanical behavior of biomedical materials 80 (2018) 111-118.

72. Y. Zhu, Y. Liu, K. Jin, Z. Pang, 13 - Polysaccharide nanoparticles for cancer drug targeting, in: S. Maiti, S. Jana (Eds.), Polysaccharide Carriers for Drug Delivery, Woodhead Publishing2019, pp. 365-396.

73. N. Alexandre, J. Ribeiro, A. Gärtner, T. Pereira, I. Amorim, J. Fragoso, A. Lopes, J. Fernandes, E. Costa, A. Santos-Silva, M. Rodrigues, J.D. Santos, A.C. Maurício, A.L. Luís, Biocompatibility and hemocompatibility of polyvinyl alcohol hydrogel used for vascular grafting-In vitro and in vivo studies, Journal of biomedical materials research. Part A 102(12) (2014) 4262-75.

74. S. Khalaji, N. Golshan Ebrahimi, H. Hosseinkhani, Enhancement of biocompatibility of PVA/HTCC blend polymer with collagen for skin care application, International Journal of Polymeric Materials and Polymeric Biomaterials (2020) 1-10.

\section{Figures}


A

\begin{tabular}{|c|r|r|r|r|r|c|}
\hline & Intercept & \multicolumn{1}{c|}{ A } & \multicolumn{1}{c|}{ B } & \multicolumn{1}{c|}{ AB } & \multicolumn{1}{c|}{ A $^{\mathbf{2}}$} & \multicolumn{1}{c|}{ B $^{2}$} \\
\hline nanofiber production & 2.96552 & -0.166667 & -0.166667 & -0.25 & $\mathbf{- 1 . 8 7 9 3 1}$ & 0.12069 \\
\hline p-values & & 0.4910 & 0.4910 & 0.4031 & $\mathbf{0 . 0 0 0 9}$ & 0.7316 \\
\hline
\end{tabular}

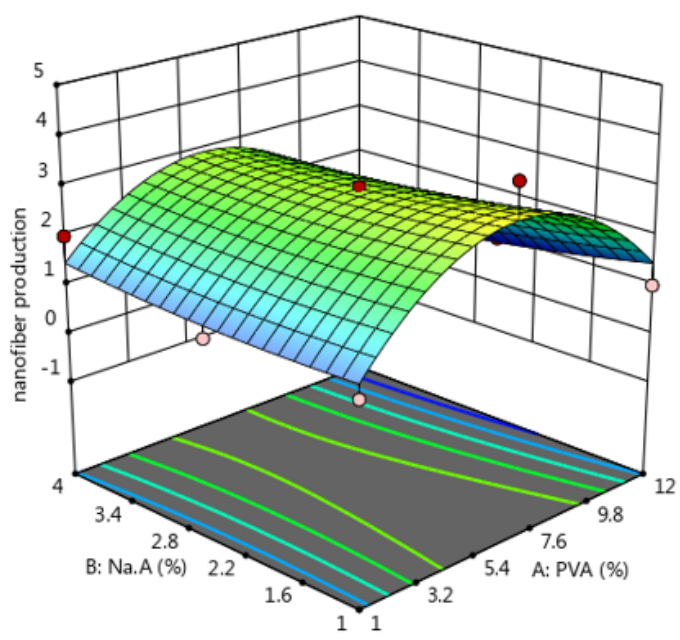

B

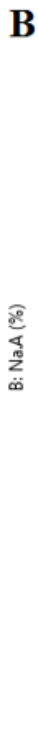

nanofiber production (-)

nanofiber production Design Points:

Above Surface Below Surface

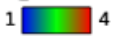

$\mathrm{X} 1=\mathrm{A}: \mathrm{PVA}$

$X 2=B: N a \cdot A$

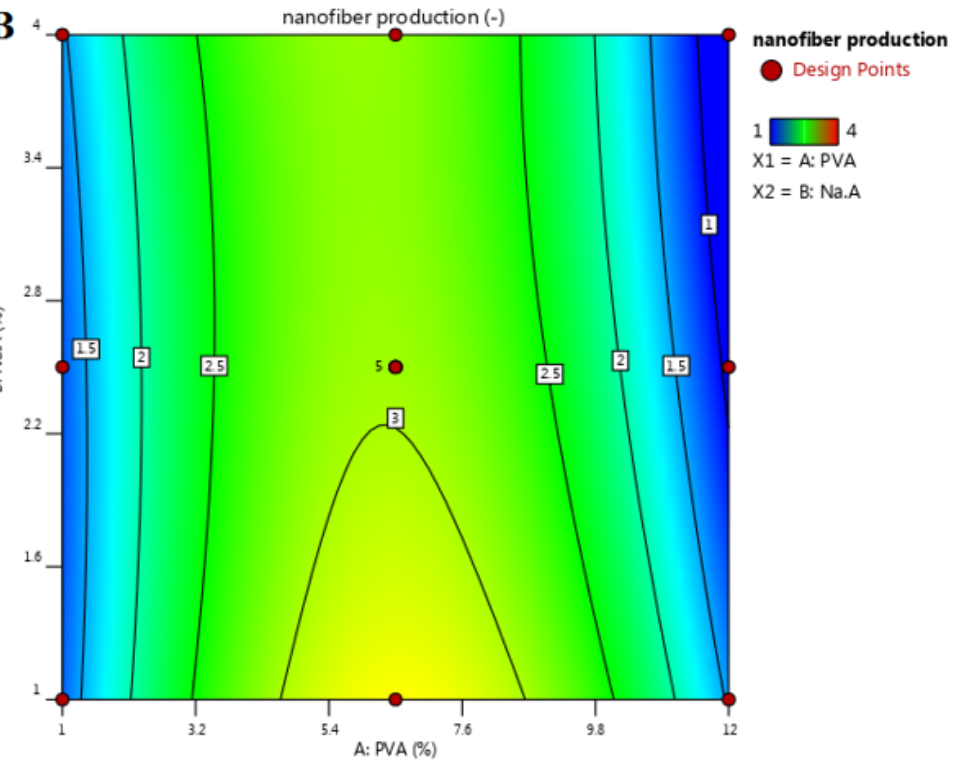

Figure 1

The effect of composition on nanofiber production: $(A)$ appropriate P-value for the main parameters and three-dimensional (3D) surface graph, and (B) counterplot. 

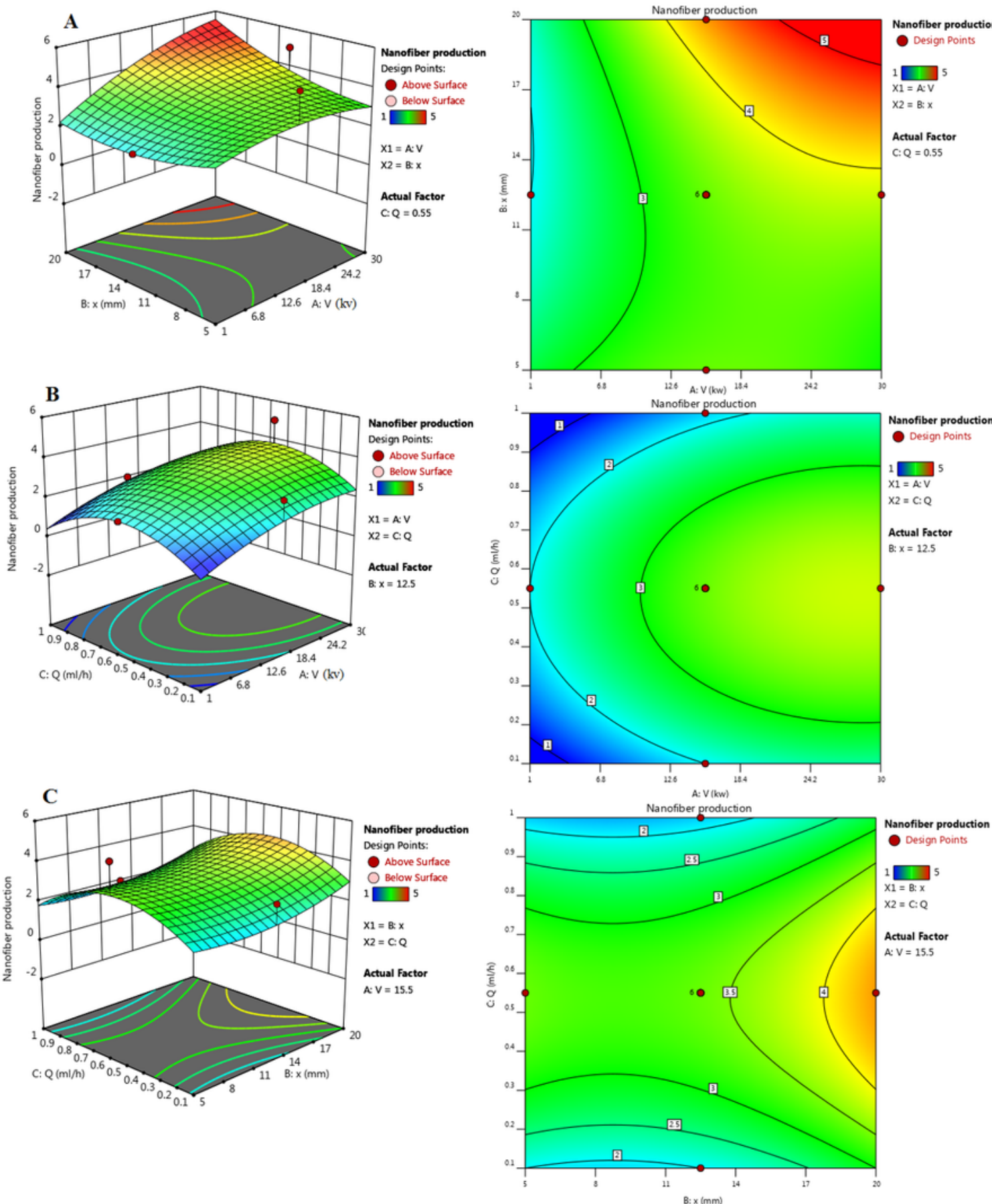

\begin{tabular}{|c|r|r|r|r|r|r|r|r|r|r|}
\hline & Intercept & \multicolumn{1}{c|}{$\mathrm{A}$} & \multicolumn{1}{c|}{$\mathrm{B}$} & \multicolumn{1}{c|}{$\mathrm{C}$} & \multicolumn{1}{|c|}{$\mathrm{AB}$} & \multicolumn{1}{c|}{$\mathrm{AC}$} & $\mathrm{BC}$ & $\mathrm{A}^{\mathbf{2}}$ & $\mathrm{B}^{2}$ & \multicolumn{1}{c|}{$\mathrm{C}^{\mathbf{2}}$} \\
\hline Nanofiber production & 3.4 & $\mathbf{0 . 9}$ & 0.5 & -0.1 & $\mathbf{0 . 7 5}$ & $-3.74015 \mathrm{E}-17$ & $-2.35514 \mathrm{E}-16$ & -0.5 & 0.5 & $\mathbf{- 1 . 5}$ \\
\hline p-values & & $\mathbf{0 . 0 0 7 0}$ & 0.0900 & 0.7153 & $\mathbf{0 . 0 3 0 5}$ & 1.0000 & 1.0000 & 0.3483 & 0.3483 & $\mathbf{0 . 0 1 4 5}$ \\
\hline
\end{tabular}

\section{Figure 2}

The effect of process parameters on nanofiber production: (left) three-dimensional (3D) surface and (right) counterplot. (A) V vs. X, (B) V vs. Q, and (C) X vs. Q. 

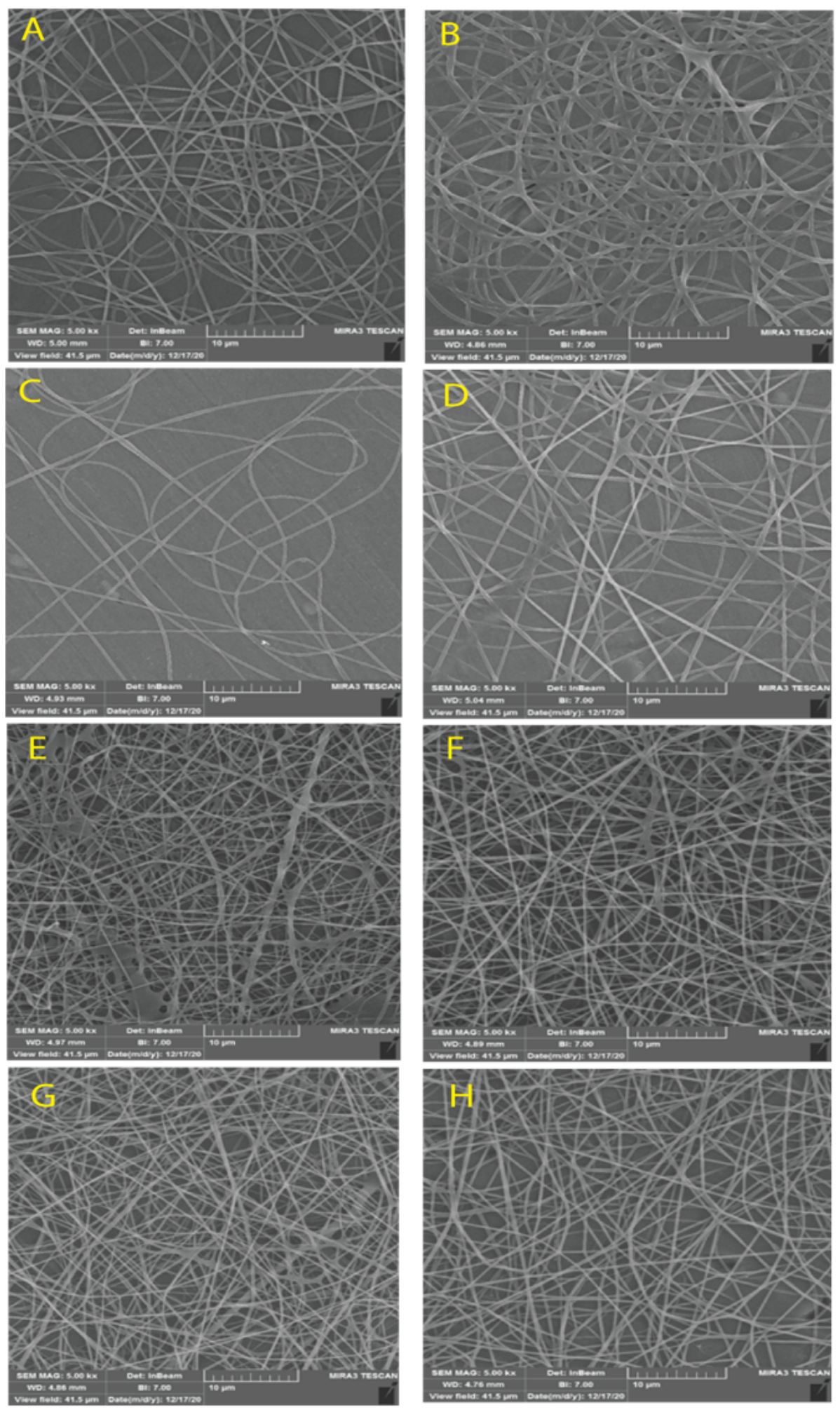

\section{Figure 3}

SEM images of the SA/PVA elestrospun scaffolds at $10 \mu \mathrm{m}$ magnificancy. SA:PVA ratio: (A) Scaffold 2,

(B) scaffold 3, (C) scaffold 5, (D) scaffold 7, (E) scaffold 12, (F) scaffold 14, (G) scaffold 15, (H) scaffold 18. 

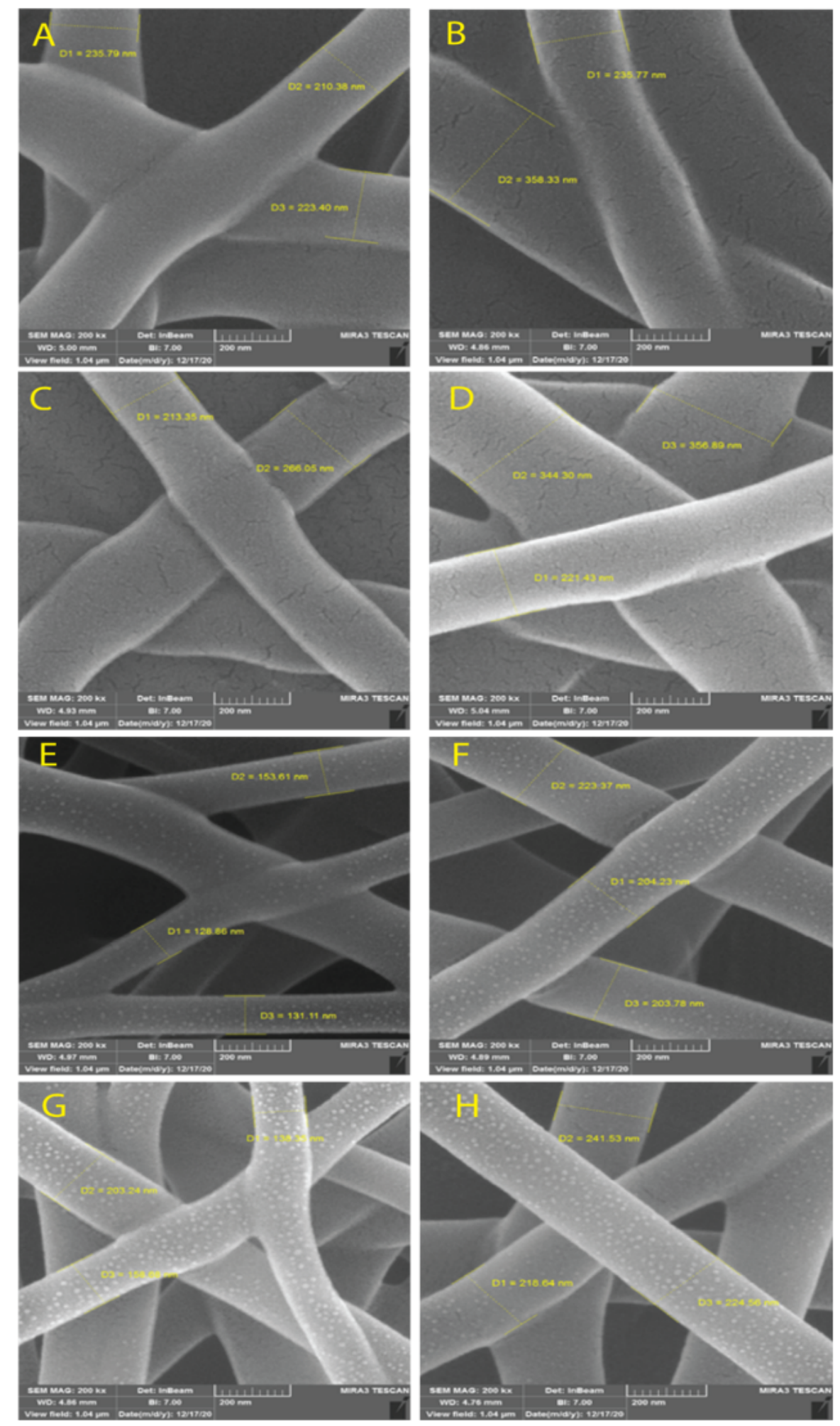

\section{Figure 4}

SEM images of the SA/PVA elestrospun scaffolds for size distribution at $200 \mathrm{~nm}$ magnificancy. SA:PVA ratio: (A) Scaffold 2, (B) scaffold 3, (C) scaffold 5, (D) scaffold 7, (E) scaffold 12, (F) scaffold 14, (G) scaffold 15, (H) scaffold 18. 


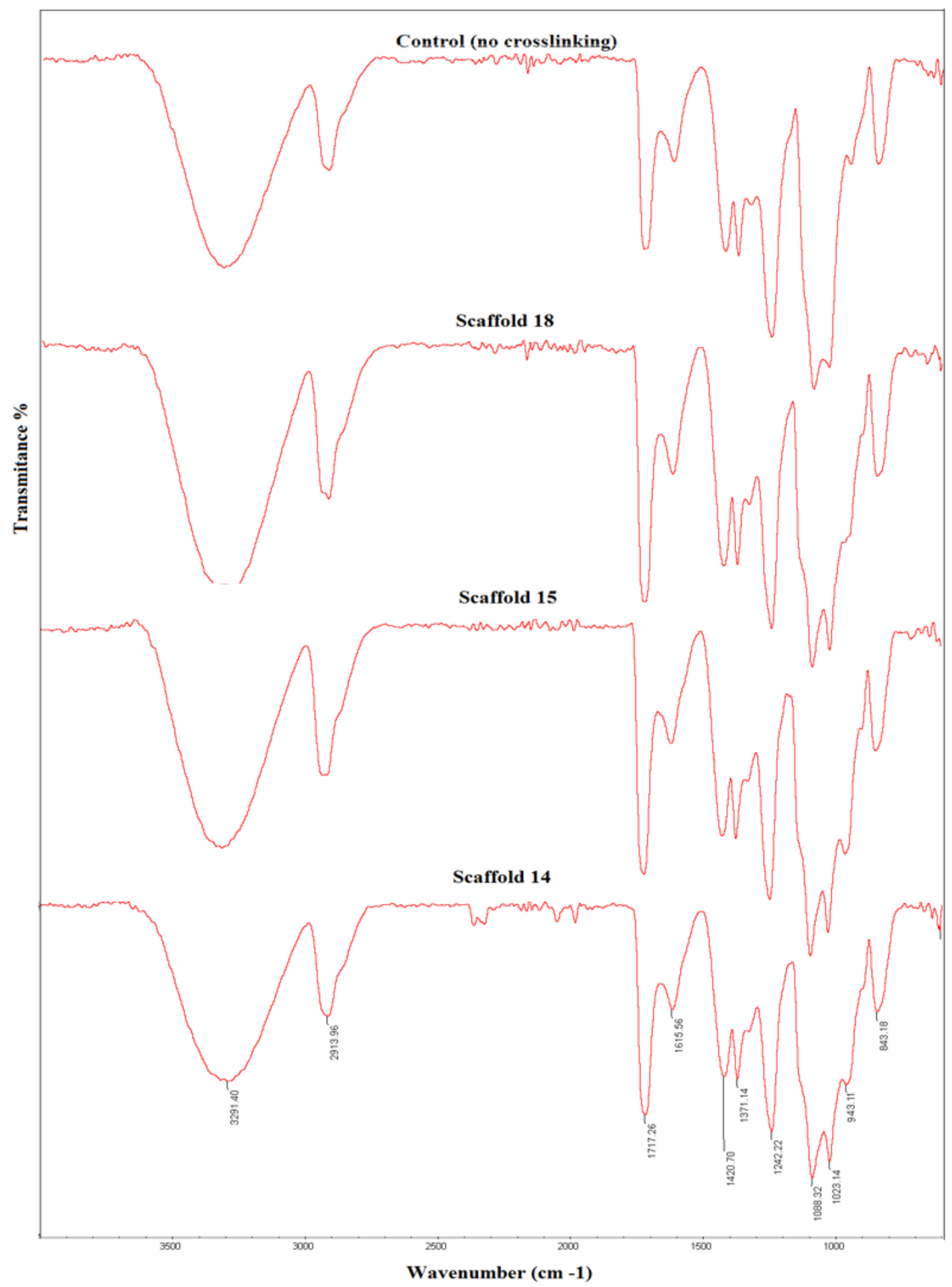

Figure 5

Fourier-transform infrared (FTIR) spectra of the elected electrospun scaffolds and their comparison with the control group which received no crosslinking. 


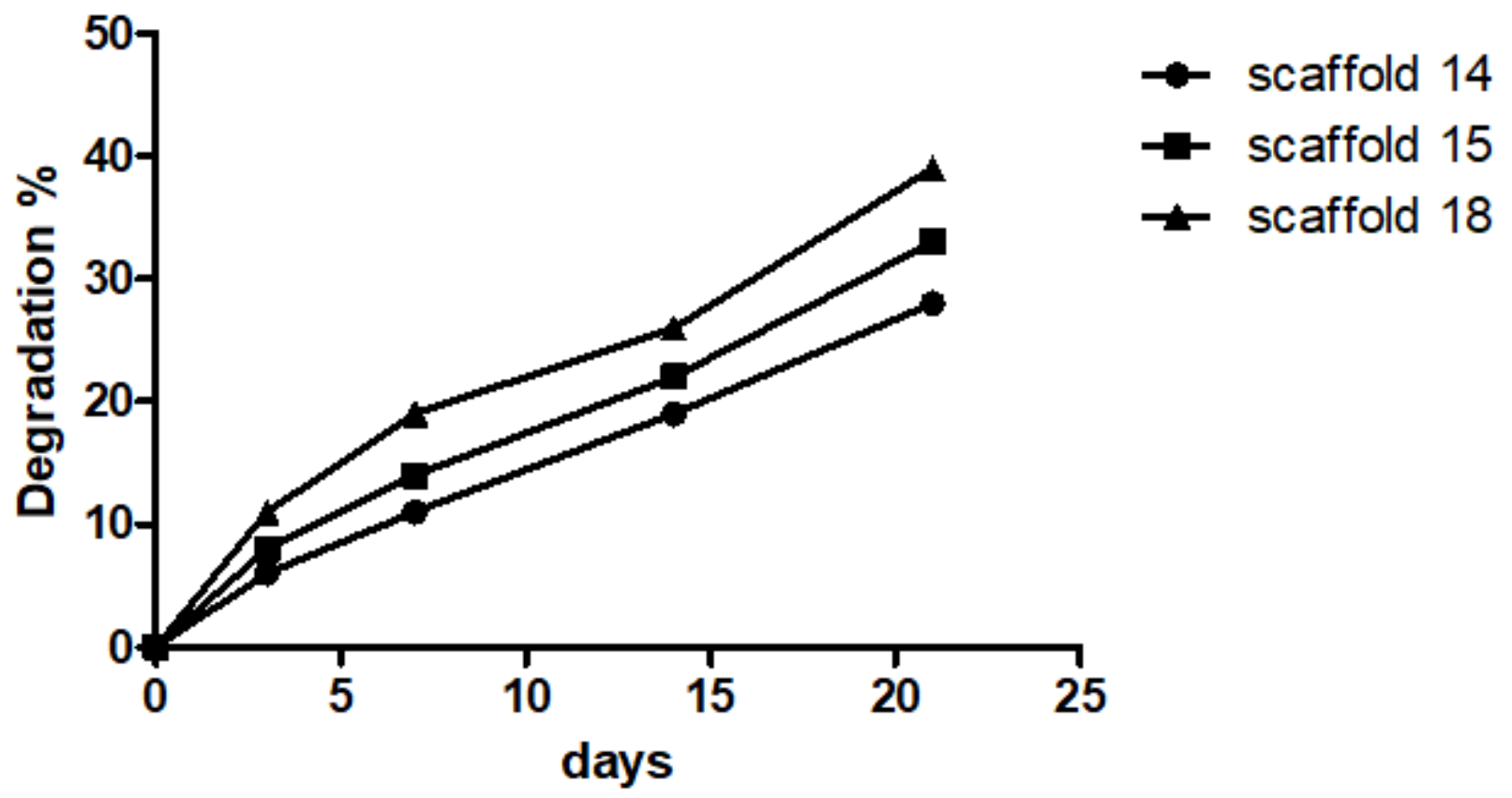

Figure 6

degradation rate of the elected electrospun scaffolds. 


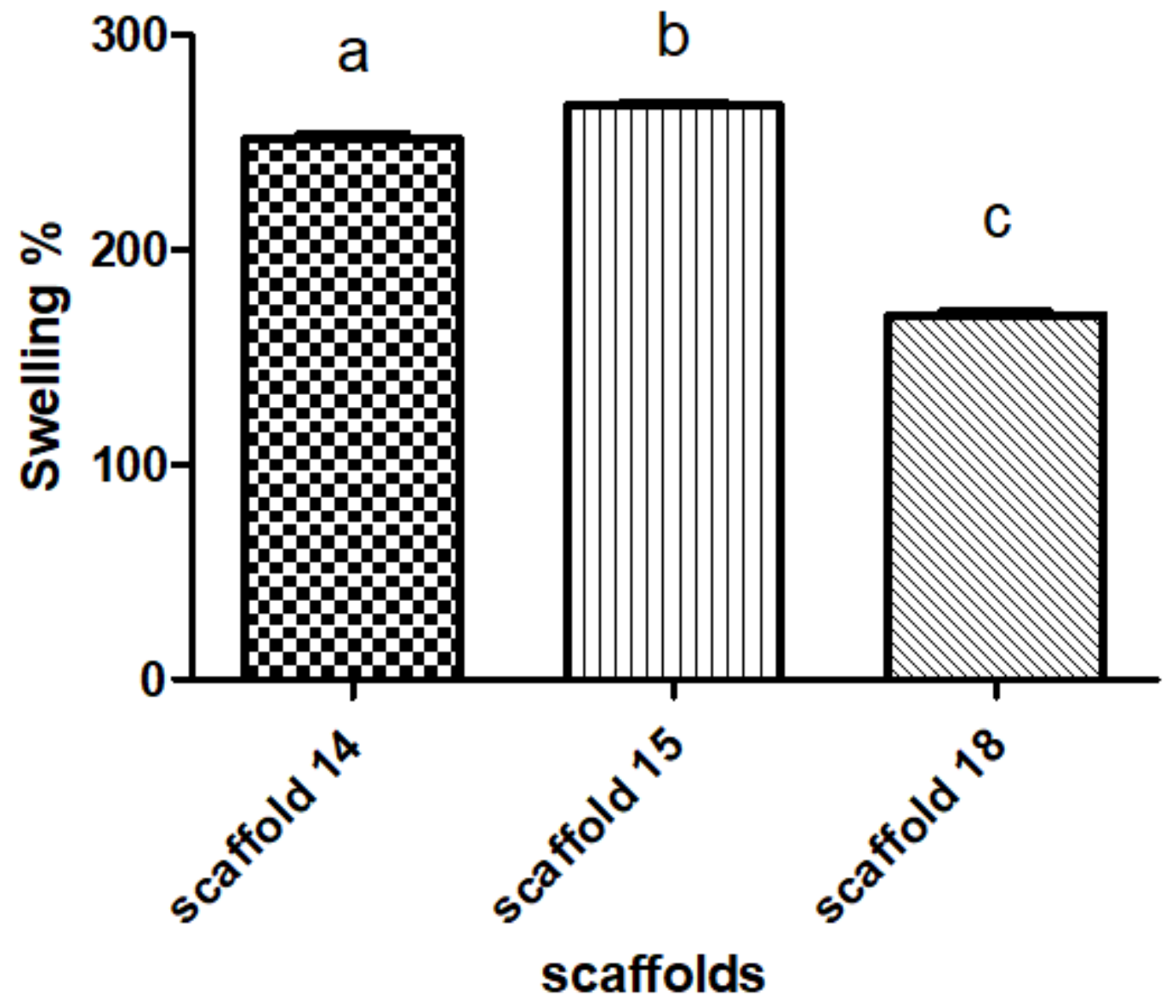

Figure 7

swelleing behaviour of the elected electrospun scaffolds.
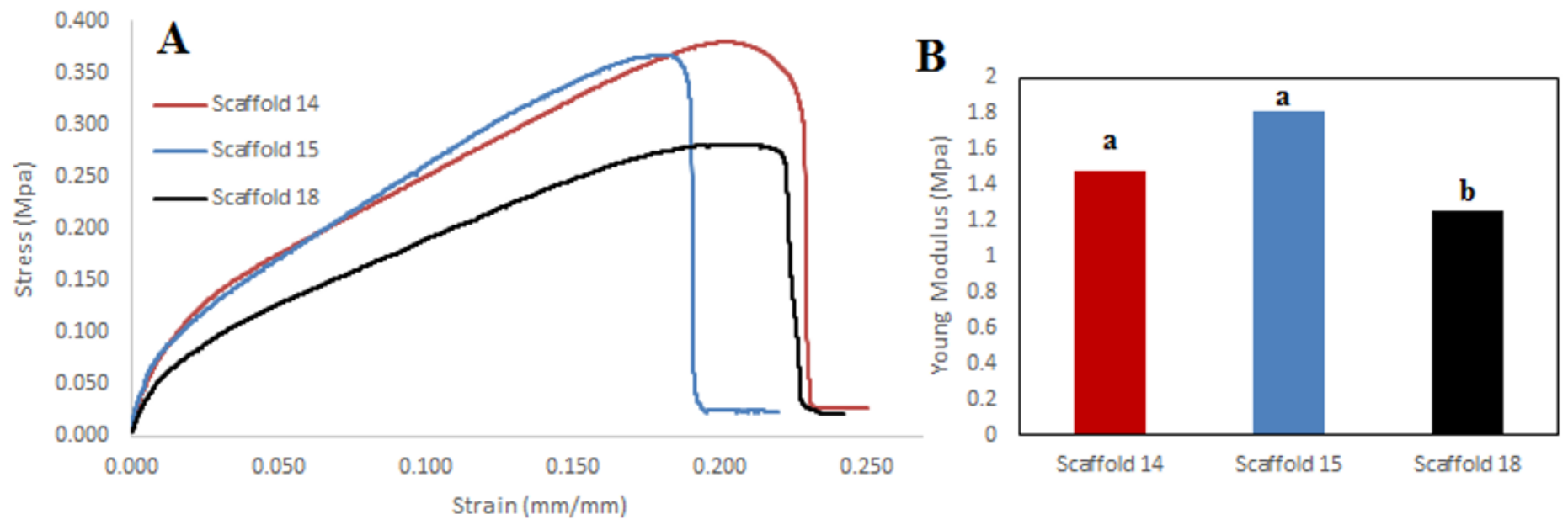

Figure 8

(A) stress-strain diagram, (B) Elastic modulus diagram for Scaffold 14, Scaffold 15, and Scaffold 18. 


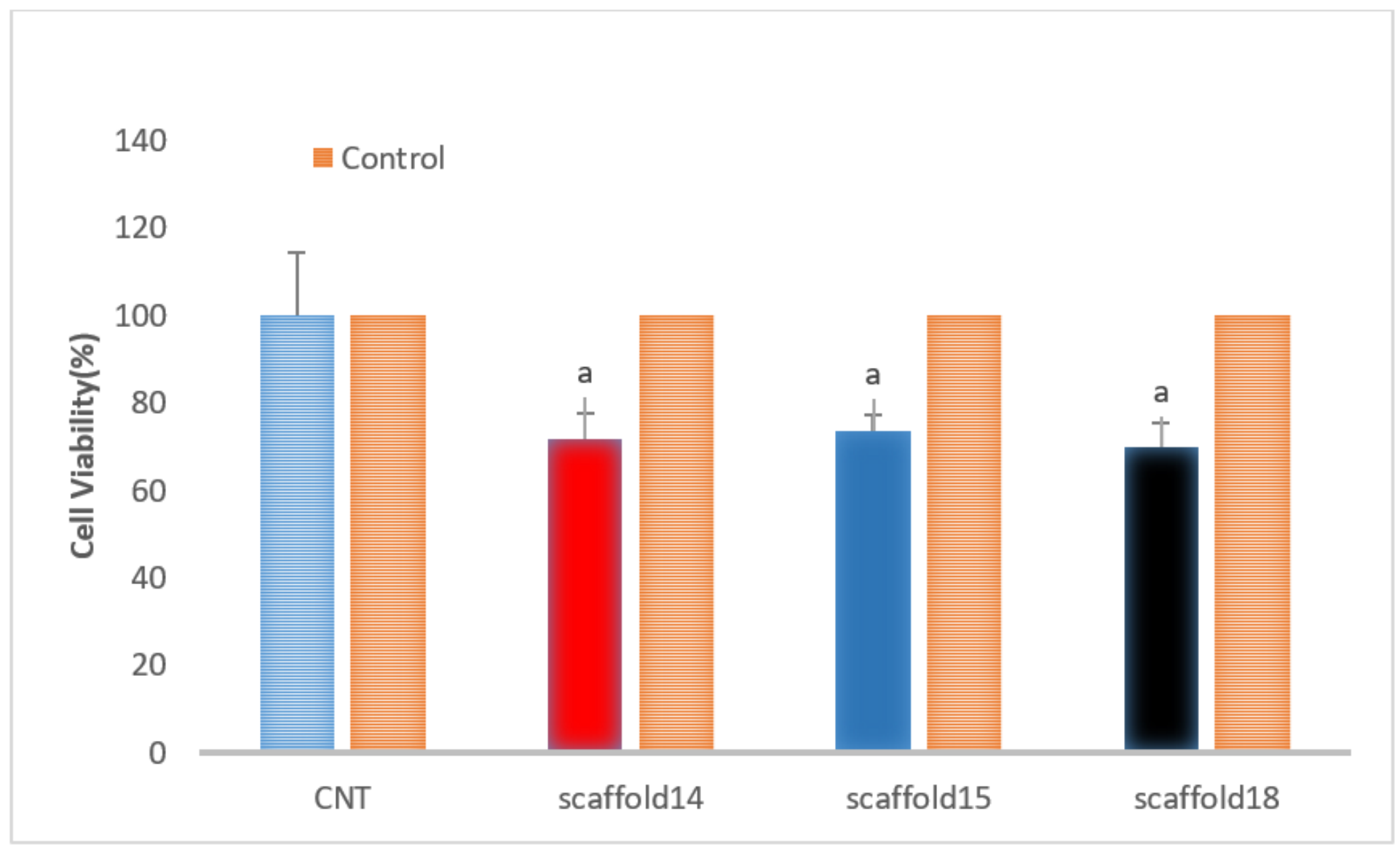

Figure 9

cell viability analysis of the elected eletrospun scaffolds. 